\title{
Dietary wheat germ agglutinin modulates ovalbumin-induced immune responses in Brown Norway rats
}

\author{
Bernhard Watzl $^{1 *}$, Christian Neudecker ${ }^{2}$, Gertrud M. Hänsch ${ }^{3}$, Gerhard Rechkemmer $^{1}$ and \\ Beatrice L. Pool-Zobel ${ }^{3} \dagger$ \\ ${ }^{1}$ Institute of Nutritional Physiology, ${ }^{2}$ Institute of Hygiene and Toxicology, Federal Research Centre for Nutrition, \\ Haid-und-Neu-Str, 9, 76131 Karlsruhe, Germany \\ ${ }^{3}$ Institute of Immunology, Ruprecht Karls University, Heidelberg, Germany
}

(Received 7 July 2000 - Revised 23 October 2000 - Accepted 1 November 2000)

\begin{abstract}
The trend towards an increased consumption of minimally processed plant food results in a higher intake of non-nutritive compounds such as lectins. Lectins are typically globular proteins that are resistant to digestion in the gastrointestinal tract. They affect the integrity of the intestinal epithelium and the absorption of dietary antigens, and induce the release of allergic mediators from mast cells in vitro. Based on this information we have studied whether dietary wheat germ agglutinin (WGA) could be involved in triggering food allergies. Brown Norway rats were immunized intraperitoneally using ovalbumin (OVA; $10 \mu \mathrm{g} / \mathrm{rat}$ ) and $10 \mathrm{~d}$ later treated for five consecutive days with WGA $(10 \mathrm{mg} / \mathrm{rat}$ per d) administered intragastrically. Rats were then orally challenged with OVA $(100 \mu \mathrm{g} / \mathrm{rat}) 1 \mathrm{~h}$ after the last WGA application, and blood was collected $4 \mathrm{~h}$ later. Immunological responses (anti-OVA immunoglobulins $\mathrm{E}$ and $\mathrm{G}$, rat mast cell protease II, interferon- $\gamma$ and lymphocyte proliferation) were measured and lymphocyte subpopulations were determined. In immunized rats WGA treatment resulted in increased serum rat mast cell protease II concentrations (pre-challenge 0.26 (SE 0.08) $\mu \mathrm{g} / \mathrm{ml}$, post-challenge 0.49 (SE 0.09) $\mu \mathrm{g} / \mathrm{ml} ; P<0.01) 4 \mathrm{~h}$ after the OVA challenge. After $5 \mathrm{~d}$ serum concentrations of antiOVA immunoglobulin E were significantly increased only in the immunized controls (absorbance at $405 \mathrm{~nm}$ on days 14 and 19 was 0.09 (SE 0.008) and 0.24 (SE 0.046) respectively; $P=0.02$ ), while in WGA-treated rats no significant increase was seen (0.08 (SE 0.004) and 0.15 (SE 0.037 respectively; $P=0 \cdot 14$ ). $\mathrm{CD}^{+}: \mathrm{CD}^{+} \mathrm{T}$ lymphocytes in the spleen was significantly increased at this time (OVA $1 \cdot 1$ (SD 0.2), OVA + WGA 1.4 (SD 0.1), $P<0 \cdot 05$ ). The treatment did not impair the proliferation and interferon- $\gamma$ production of mesenteric lymphocytes. In conclusion, these data suggest that high dietary intake of lectins such as WGA may affect the allergic response towards oral antigens in the gut-associated lymphoid tissue.
\end{abstract}

Wheat germ agglutinin: Immune response: Allergy

Recent dietary recommendations have emphasized the increased consumption of whole-wheat products (World Cancer Research Fund and American Institute for Cancer Research, 1997). This may result in an elevated dietary intake of lectins such as wheat-germ agglutinin (WGA). The health effects of dietary lectins have recently been addressed by several authors who have pointed out that currently only limited information is available on the immunotoxicity of lectins (Freed, 1999; Kilpatrick, 1999;
Cordain et al. 2000). Lectins occur in many crop plants and are part of the normal diet (Nachbar \& Oppenheim, 1980). They are typically globular proteins that are resistant to digestion by mammalian and bacterial enzymes and may pass intact through the gastrointestinal tract. Lectins may further become internalized and circulate intact in the peripheral blood (Pusztai et al. 1993; Wang et al. 1998). They provoke diverse biological consequences in mammals such as hyperplasia and hypertrophy of the small intestine

\footnotetext{
Abbreviations: BN, Brown Norway; GALT, gut-associated lymphoid tissue; Ig, immunoglobulin; IFN $\gamma$, interferon- $\gamma$; IL, interleukin; OVA, ovalbumin; RMCPII, rat mast cell protease II; WGA, wheat-germ agglutinin.

* Corresponding author: Dr B. Watzl, fax + 497216625 404, email bernhard.watzl@ bfe.uni-karlsruhe.de

$\dagger$ Present address: Department of Nutritional Toxicology, Institute for Nutrition, Friedrich Schiller University, Jena, Germany.
} 
and could increase the permeability of the intestinal wall, resulting in enhanced absorption of dietary antigens (Pusztai, 1991; Freed, 1999; Kilpatrick, 1999; Cordain et al. 2000).

There are no data available on the average dietary intake of WGA in human subjects. In cereals, WGA concentrations ranged from 13 to $53 \mathrm{mg} / \mathrm{kg}$ (OrtegaBarria et al. 1994). The highest WGA concentrations are found in wheat germ $(\leq 0.5 \mathrm{~g} / \mathrm{kg} ;$ Peumans \& van Damme, 1996). The estimated quantity of total dietary lectins is in the range $0-200 \mathrm{mg} /$ person per $\mathrm{d}$ (calculations based on data from Peumans \& van Damme, 1996). Such a dose range is expected to be too low to induce non-nutritive or toxic effects in the gastrointestinal tract (Peumans \& van Damme, 1996). In volunteers consuming wheat germ with the equivalent of $200 \mathrm{mg}$ active agglutinin, no side effects were reported (Brady et al. 1978). In another group of volunteers the consumption of whole wheat resulted in the generation of serum antiWGA antibodies (Tchernychev \& Wilchek, 1996), indicating that intact WGA passes through the intestinal wall and reaches cells of the gut-associated lymphoid tissue (GALT) located in the lamina propria. Only few data are currently available on the immunotoxicity of orally administered WGA on the GALT (Pusztai et al. 1993), although this is probably the immune tissue with the highest WGA exposure. The immunological consequences of the trans-epithelial transport of intact WGA from the diet are unknown.

In the rat WGA binds to surface glycans on epithelial cells causing damage to the base of the villi. The resulting structural changes include increased intestinal permeability for different permeability markers (Pusztai et al. 1993). In tissue culture experiments WGA blocked as well as enhanced the epithelial permeability of various permeability markers, depending on their molecular size (Lorenzsonn \& Olsen, 1982; Sjölander et al. 1984). In vitro WGA interacts with the interleukin (IL) 2 receptor on $\mathrm{T}$ and $\mathrm{B}$ lymphocytes, and thereby impairs lymphocyte function (Pusztai, 1991). WGA binds to immunoglobulin (Ig) on leucocytes from allergic patients and induces histamine secretion (Shibasaki et al. 1992), it stimulates histamine release by murine peritoneal non-sensitized mast cells (Lansman \& Cochrane, 1980) as well as IL-4 and IL13 secretion by human basophils (Haas et al. 1999). These cytokines are key promotors of both T-helper 2 lymphocyte responses and IgE synthesis. Such in vitro activities suggest a potential of WGA-rich food to stimulate allergic responses to dietary antigens.

The hypothesis of the present study was that WGA could impair the intestinal epithelial integrity, thereby facilitating the penetration of antigens and impairing the tolerance of the gut towards these antigens. In addition, WGA might further directly interact with mucosal mast cells and nonspecifically induce mediator release. The objective of the present study was to investigate whether toxic effects of WGA in the intestinal tissue could be involved in triggering food allergies. An established animal model (Watzl et al. $1999 a, b)$ was used to study whether dietary WGA affected the immune response to intragastrically applied ovalbumin (OVA) in immunized Brown Norway (BN) rats.

\section{Materials and methods}

\section{Materials}

WGA was purchased from Sigma (Deisenhofen, Germany). Fetal bovine serum, glutamine, penicillin and streptomycin were obtained from Boehringer (Mannheim, Germany). Reagents for immunofluorescence staining were all from Pharmingen (Hamburg, Germany). Antibodies were purchased from Sera Lab, Crawley Down, West Sussex, UK (anti-rat IgE), from The Binding Site, Heidelberg, Germany (anti-rat IgG), and from Southern Biotechnology, Birmingham, AL, USA (anti-mouse $\mathrm{IgG}_{1}$ ). All the other reagents were obtained from Sigma.

\section{Animals and treatment schedule}

Adult male $\mathrm{BN}$ rats were obtained from the breeding colony of the Federal Research Centre for Nutrition, Karlsruhe, Germany. Permission for the animal studies was obtained from the State Veterinary Office and experiments were performed in compliance with their guidelines for the care and use of laboratory animals. BN rats were fed ad libitum with a WGA- and OVA-free diet (C1000; Altromin, Lage, Germany); 12 h before substance application and before termination of the experiment, feeding was stopped. All test substances were administered intragastrically by tube. OVA and WGA were dissolved in $1 \mathrm{ml}$ saline $(9 \mathrm{~g} \mathrm{NaCl} / \mathrm{l})$.

$\mathrm{BN}$ rats (six to eight rats per treatment) were immunized intraperitoneally on day 0 using $1 \mathrm{ml} \mathrm{OVA}(10 \mu \mathrm{g} / \mathrm{ml})$ dissolved in saline without use of an adjuvant. Control animals were treated intraperitoneally with $1 \mathrm{ml}$ saline. During days 10-14, rats were treated for five consecutive days: group A, non-immunized control animals were treated with $1 \mathrm{ml}$ saline/d; group $\mathrm{B}$, immunized rats were treated with $1 \mathrm{ml}$ saline/d; group $\mathrm{C}$, immunized rats were treated with $10 \mathrm{mg}$ WGA $(27 \mathrm{mg} / \mathrm{kg}$ body weight $) / \mathrm{d}$. At $1 \mathrm{~h}$ after the last treatment with WGA, the animals of all three groups were challenged orally with $100 \mu \mathrm{g}$ OVA/rat dissolved in $1 \mathrm{ml}$ saline. Doses of OVA were based on previous experiments (Watzl et al. 1999a,b). The dose of WGA was chosen to be ten times higher than the average total dietary intake of lectins in human subjects consuming vegetarian diets (calculations based on data from Peumans \& van Damme, 1996).

\section{Blood collection}

Blood was obtained from the tail vein at different time points during the experiment, and at the end of the experiments from the axillary plexus of rats anaesthetized with diethyl ether. Serum was obtained and stored at $-20^{\circ} \mathrm{C}$ until further processing.

\section{Cell isolation and culture}

Lymphocytes were isolated from spleen and mesenteric lymph nodes and were suspended in RPMI 1640 medium, supplemented with $10 \mathrm{mM}$-HEPES buffer solution, and $5 \%(\mathrm{v} / \mathrm{v})$ heat-inactivated fetal bovin serum, 
2-mercaptoethanol $(50 \mu \mathrm{M})$, L-glutamine $(2 \mathrm{mmol} / \mathrm{l})$, penicillin $(100 \mathrm{U} / \mathrm{ml})$, and streptomycin $(100 \mu \mathrm{g} / \mathrm{ml})$.

\section{Immunofluorescence staining}

Cells from the spleen and from the mesenteric lymph nodes adjusted to a density of $1 \times 10^{6}$ cells $/ \mathrm{ml}$ were washed three times with PBS containing $1 \%(\mathrm{w} / \mathrm{v})$ bovine serum albumin and $0.1 \%(\mathrm{w} / \mathrm{v})$ sodium azide. The cells were incubated for $30 \mathrm{~min}$ at $4^{\circ} \mathrm{C}$ with fluoresceinisothiocyanate-conjugated anti-rat $\mathrm{CD} 4$, and fluoresceinisothiocyanate-conjugated anti-rat CD8. After three washes with cold fluorescence-activated cell sorter buffer, cells were fixed with $1 \%(\mathrm{v} / \mathrm{v})$ paraformaldehyde and analysed using a FACScan fluorescence-activated cell sorter (Becton Dickinson, Heidelberg, Germany).

\section{Lymphocyte proliferation}

Mesenteric lymph node cells at $1 \times 10^{6}$ cells $/ \mathrm{ml}$ were stimulated by the T-cell mitogen concanavalin A $(5 \mu \mathrm{g} / \mathrm{ml})$ for $120 \mathrm{~h}$. The cells were pulse-labelled with the thymidine analogue 5-bromo-deoxyuridine for $2 \mathrm{~h}$ at $37^{\circ} \mathrm{C}$. The incorporated 5-bromo-deoxyuridine was detected by a quantitative cellular enzyme immunoassay using a commercial ELISA kit according to the instructions of the manufacturer (Boehringer Mannheim).

\section{Detection of rat mast cell protease II in serum}

The concentration of rat mast cell protease II (RMCPII) in serum was measured by ELISA (Huntley et al. 1990) with the use of a commercially-available kit (Moredun Scientific Limited, Midlothian, UK).

\section{Detection of specific anti-ovalbumin immunoglobulins $E$ and $G$}

Anti-OVA antibody serum levels were measured by ELISA as reported earlier (Watzl et al. 1999a). Briefly, microtitre plates (Maxisorp; NUNC, Roskilde, Denmark) were coated with $50 \mu \mathrm{l}$ per well of an OVA solution $(20 \mu \mathrm{g} / \mathrm{ml})$. Sera diluted at $1 / 100$ were added for $2 \mathrm{~h}$ at room temperature. For detection of $\mathrm{IgE}$, plates were incubated with a monoclonal mouse anti-rat $\operatorname{IgE}$ antibody followed by a polyclonal affinity-purified goat anti-mouse $\mathrm{IgG}_{1}$ peroxidase-conjugated antibody. As a peroxidase substrate, $2,2^{\prime}-$ azino-bis-3-ethylbenzothiazoline-6-sulfonic acid buffer was used. Optical density was measured at $405 \mathrm{~nm}$. For the detection of IgG, a polyclonal affinity-purified sheep anti-rat $\operatorname{IgG}$ peroxidase-conjugated antibody was used. There was no cross-reactivity between the monoclonal mouse anti-rat IgE antibody and the rat anti-OVA IgG antibody in serum.

\section{Detection of interferon- $\gamma$ in culture supernatant fractions}

Mesenteric lymphocytes at $1 \times 10^{7}$ cells $/ \mathrm{ml}$ in complete RPMI 1640 medium were stimulated by $5 \mu \mathrm{g}$ concanavalin $\mathrm{A} / \mathrm{ml}$ for $48 \mathrm{~h}$ at $37^{\circ} \mathrm{C}$. Cell-free supernatant fractions were collected and stored at $-80^{\circ} \mathrm{C}$ for later analysis. Interferon- $\gamma$
(IFN $\gamma$ ) was quantified by ELISA as described earlier (Watzl et al. 1999a).

\section{Measurement of intestinal epithelial permeability}

Caco-2 cells (European Collection of Animal Cell Cultures) were used at passage 30-45 and were plated on Transwell ${ }^{\circledR}$ cell culture chamber inserts $\left(1 \mathrm{~cm}^{2}\right.$, pore size $3 \mu \mathrm{m}$, polycarbonate membrane; Costar, Bodenheim, Germany) that had been coated with rat-tail collagen $\left(25 \mu \mathrm{g} / \mathrm{cm}^{2}\right)$. Cells were cultured in Dulbecco's modified Eagle's minimum essential medium (with $4.5 \mathrm{~g}$ glucose/l and 25 mM-HEPES), supplemented with $2 \mathrm{mM}$-glutamine, $1 \mathrm{mM}$-pyruvate, $25 \mathrm{IU}$ penicillin/ml, $25 \mathrm{mg}$ streptomycin/ $\mathrm{ml}, 1 \%(\mathrm{v} / \mathrm{v})$ of a mixture of non-essential amino acids and $10 \%(\mathrm{v} / \mathrm{v})$ fetal bovine serum. Cells were maintained at $37^{\circ} \mathrm{C}$ in a humidified atmosphere of $5 \%(\mathrm{v} / \mathrm{v}) \mathrm{CO}_{2}$ in air. Culture medium was replaced three times weekly, and cells were used $14-23 \mathrm{~d}$ after trypsinization, and $1 \mathrm{~d}$ after the culture medium had been changed.

Fluorescein transport across cells grown on permeable supports was assessed as follows. For all experiments, cells were incubated in Ringer solution containing (mM): 120 $\mathrm{NaCl}, 25 \mathrm{NaHCO}_{3}, 0 \cdot 8 \mathrm{~K}_{2} \mathrm{HPO}_{4}, 3.3 \mathrm{KH}_{2} \mathrm{PO}_{4}, 1.25 \mathrm{MgCl}_{2}$, $1.25 \mathrm{CaCl}_{2}, 25 \mathrm{D}$-glucose. In order to assess the integrity of the cell monolayer, the trans-epithelial electrical resistance of each insert was measured at the start and at the end of each experiment, by means of an EVOM resistance meter and Endohm 12 chamber (World Precision Instruments, Mauer, Germany). The apical side of the Caco-2 monolayer was exposed for $2 \mathrm{~h}$ to WGA $(0.1$ and $1.0 \mathrm{mg} \mathrm{PBS} / \mathrm{ml})$. Fluorescein (free acid) in PBS was added together with the lectin. The permeability of fluorescein was measured in quadruplicate in four independent experiments as described earlier (Shaw et al. 1990).

\section{Statistics}

Baseline data $v$. post-treatment data within groups were analysed using Student's paired $t$ test or Wilcoxon's rank test for data that were not normally distributed. Differences between treatment groups were analysed using Student's $t$ test for independent samples (or the Mann-Whitney U test for data that were not normally distributed). Data from the in vitro experiments were analysed using Student's unpaired $t$ test. Statistical significance was accepted at the $P<0.05$ level.

\section{Results \\ Permeability of Caco-2 monolayer}

Caco-2 cells were cultured for 5 weeks on inserts. Confluence of the monolayer was controlled by measuring the trans-epithelial electrical resistance (mean 293 (SD 11.2) $\Omega \cdot \mathrm{cm}^{2}, n 4$ ). Caco-2 cells were incubated for $2 \mathrm{~h}$ with the permeability probe fluorescein and various doses of WGA $(0,0 \cdot 1$ and $1 \mathrm{mg} / \mathrm{ml})$. The treatment with WGA tended to increase the permeability of the monolayer for fluorescein (expressed as absorbance at $492 \mathrm{~nm}$ in the lower compartment); however, the difference was not 
statistically significant (control 0.040 (SD 0.032), $1 \mathrm{mg}$ $\mathrm{WGA} / \mathrm{ml} 0.090$ (SD 0.083), $P=0 \cdot 35, n 4)$.

\section{Humoral systemic immune response}

In order to study whether multiple exposures to WGA modulate the immune response to OVA, immunized rats were additionally treated for five consecutive days with WGA $(10 \mathrm{mg} / \mathrm{rat}$ per d). In immunized control animals treated with saline, the oral OVA challenge on day 14 resulted $5 \mathrm{~d}$ later in a significantly increased serum antiOVA IgE concentration $(P=0 \cdot 02)$. In contrast, in animals treated with WGA no significant increase in serum antiOVA IgE was observed $(P=0 \cdot 14$; Fig. 1$)$. Serum antiOVA IgG was also not significantly increased in WGA-treated rats (absorbance at $405 \mathrm{~nm}$ on days 14 and 19: OVA 0.22 (SD 0.07) and 0.50 (SD 0.09) respectively, $P=0.02 ;$ OVA + WGA 0.18 (SD 0.03) and 0.28 (SD 0.09) respectively, $P=0.34$ ).

\section{Serum rat mast cell protease II concentration}

The oral challenge of $\mathrm{BN}$ rats with OVA + WGA on day 14 resulted $4 \mathrm{~h}$ post-challenge in a significantly increased serum RMCPII concentration compared with days 0 and 19 $(P<0.05$; Fig. 2). RMCPII concentrations on day 14 did not differ significantly between OVA + WGA and OVA alone $(P=0 \cdot 11)$. In rats treated with only OVA no effect on mucosal RMCPII secretion was observed.

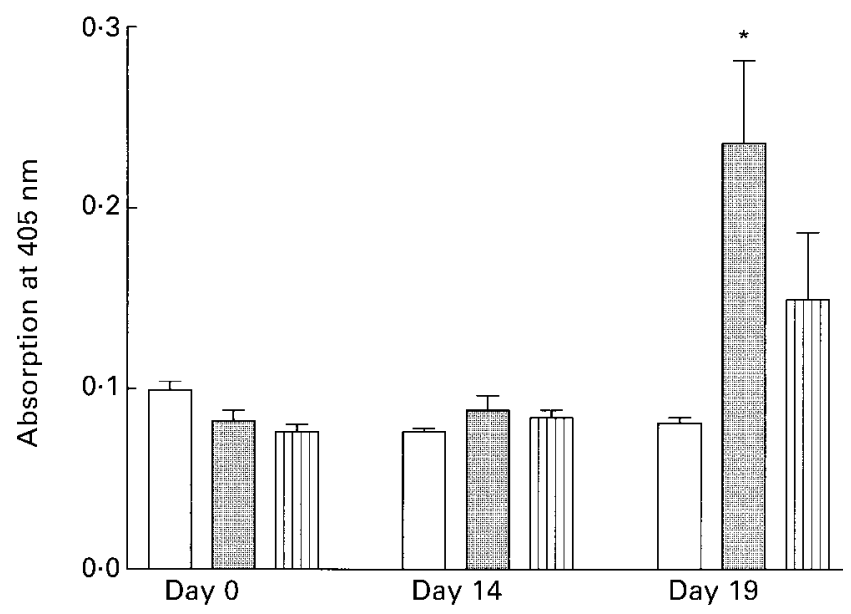

Fig. 1. Anti-ovalbumin (OVA) immunoglobulin E serum concentrations in immunized Brown Norway rats. Blood was collected before immunization (day 0), $4 \mathrm{~h}$ (day 14) and $5 \mathrm{~d}$ (day 19) after oral OVA challenge (100 $\mu \mathrm{g} / \mathrm{rat})$. Rats were treated with wheat-germ agglutinin (WGA) during days $10-14(10 \mathrm{mg} / \mathrm{rat}$ per d). For details of treatments and experimental procedures, see pp. 484-485. ( $\square$ ), Control; (घ), OVA; (四), OVA + WGA. Values are means and standard errors of the means represented by vertical bars for six to eight rats per treatment. Mean value for OVA on day 19 was significantly different for those on days 0 and $14:{ }^{*} P<0.05$.

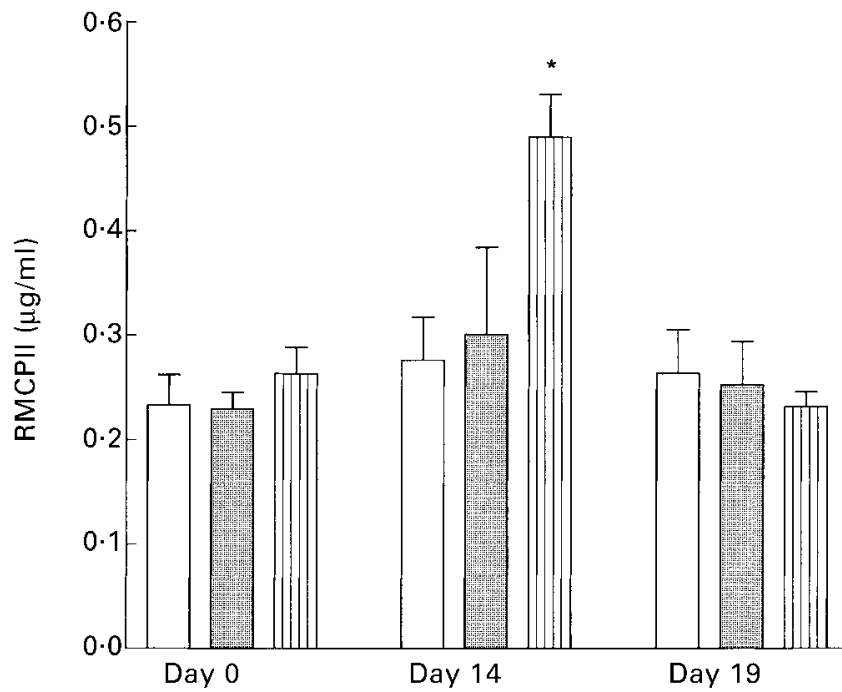

Fig. 2. Rat mast cell protease II (RMCPII) concentrations in serum of immunized Brown Norway rats. Blood was collected before immunization (day 0), $4 \mathrm{~h}$ (day 14) and $5 \mathrm{~d}$ (day 19) after oral ovalbumin (OVA) challenge (100 $\mu \mathrm{g} / \mathrm{rat})$. Rats were treated with wheat-germ agglutinin (WGA) during days 10-14 (10 mg/rat per d). For details of treatments and procedures, see pp. 484-485. ( $\square$ ),

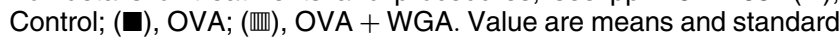
errors of the means represented by vertical bars for six to eight rats per treatment. Mean value for OVA + WGA on day 14 was significantly different from those on days 0 and 19: ${ }^{*} P<0.05$.

\section{Proliferation of mesenteric lymphocytes and secretion of interferon- $\gamma$}

The treatment of rats with WGA did not affect the proliferative responsiveness of ConA-activated mesenteric lymphocytes when compared with untreated immunized rats (Fig. 3). However, mesenteric lymphocytes from immunized animals showed a significantly enhanced proliferative responsiveness compared with lymphocytes

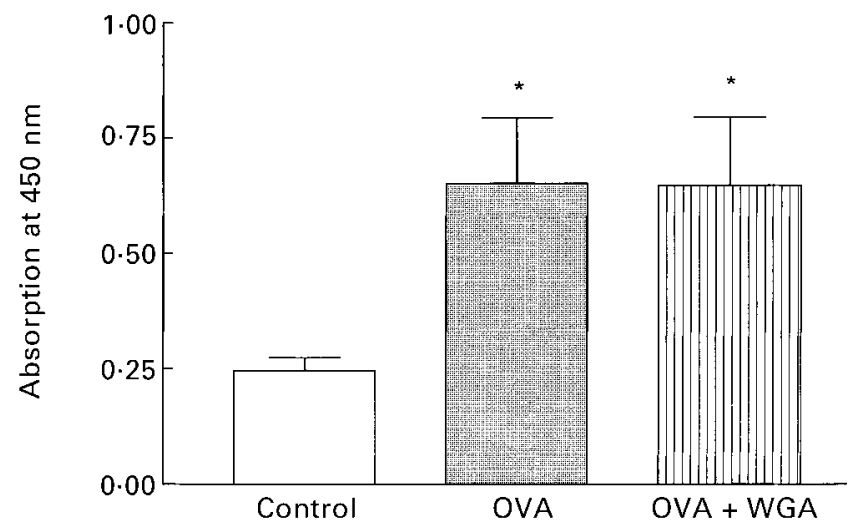

Fig. 3. Proliferation of mesenteric lymphocytes from Brown Norway rats activated by concanavalin $\mathrm{A}(5 \mu \mathrm{g} / \mathrm{ml})$ for $120 \mathrm{~h}$ at $37^{\circ} \mathrm{C}$. Lymphocytes were isolated $5 \mathrm{~d}$ after oral ovalbumin (OVA) challenge $(100 \mu \mathrm{g} / \mathrm{rat})$ and the last wheat-germ agglutinin (WGA) treatment $(5 \times 10 \mathrm{mg} \mathrm{WGA} / \mathrm{rat})$. For details of treatments and procedures, see

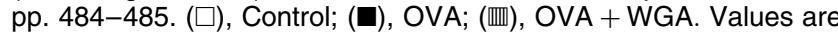
means and standard errors of the means represented by vertical bars for six to eight rats per treatment. Mean values were significantly different from that for the controls: ${ }^{*} P<0.05$. 


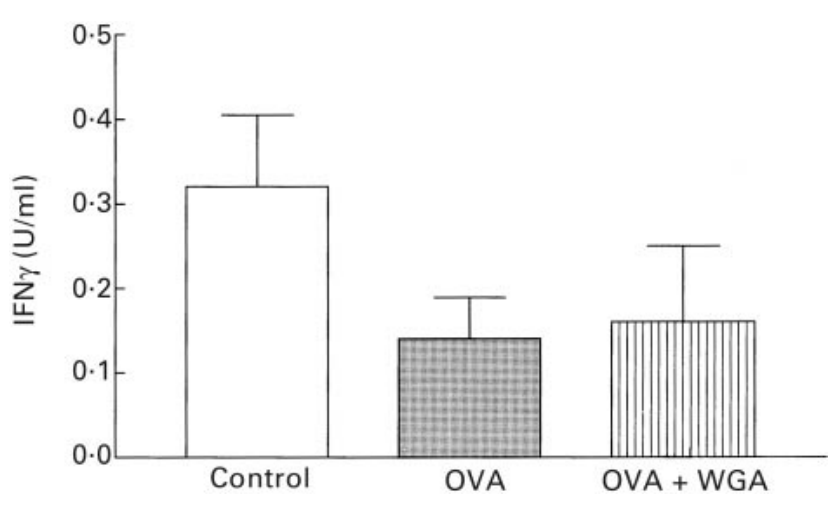

Fig. 4. Secretion of interferon- $\gamma$ (IFN $\gamma)$ by concanavalin A $(5 \mu \mathrm{g} / \mathrm{ml})$ activated mesenteric lymphocytes from Brown Norway rats. Lymphocytes were isolated $5 \mathrm{~d}$ after oral ovalbumin (OVA) challenge $(100 \mu \mathrm{g} / \mathrm{rat})$ and the last wheat-germ agglutinin (WGA) treatment $(5 \times 10 \mathrm{mg} \mathrm{WGA} / \mathrm{rat})$. For details of treatments and procedures, see pp. 484-485. ( $\square$ ), Control; (ロ), OVA; (四), OVA + WGA. Values are means and standard errors of the means represented by vertical bars for six to eight rats per treatment.

from non-immunized rats $(P<0.05$; Fig. 3). In contrast, mesenteric lymphocytes from immunized rats showed a trend towards lower secretion of IFN $\gamma$ compared with those from non-immunized rats (OVA, $P=0.08$; OVA + WGA, $P=0.22)$ with no differences between OVA + WGA and OVA alone (Fig. 4).

\section{Detection of lymphocyte surface molecule expression}

The quantification of the expression of mesenteric lymphocyte surface molecules (CD4, CD8) revealed no impact of the WGA treatment (Table 1). However, in the spleen a lower number of $\mathrm{CD}^{+}$lymphocytes were found in rats treated with OVA + WGA (Table 1), resulting in CD4 : CD8 of $1.4(\operatorname{SD~0.1)~v.~1.1~(SD~0.2)~for~OVA-treated~}$ rats $(P<0.05)$.

Table 1. Expression of surface molecules on lymphocytes from mesenteric lymph nodes and the spleen (\% total leucocytes) of Brown Norway rats after multiple treatments with wheat-germ agglutinin (WGA $5 \times 10 \mathrm{mg} /$ rat) and subsequent oral challenge by ovalbumin (OVA; $100 \mu \mathrm{g} / \mathrm{rat}$ ) at the termination of the experiment $5 \mathrm{~d}$ after oral challenge $\dagger$

(Means and standard deviations for six to eight rats per treatment)

\begin{tabular}{|c|c|c|c|c|c|c|}
\hline & \multicolumn{2}{|c|}{ Control } & \multicolumn{2}{|c|}{ OVA } & \multicolumn{2}{|c|}{ OVA + WGA } \\
\hline & Mean & $S \mathrm{SD}$ & Mean & $\overline{S D}$ & Mean & SD \\
\hline \multicolumn{7}{|c|}{ Mesenteric lymph nodes } \\
\hline CD4 (\%) & $40 \cdot 2$ & $2 \cdot 3$ & 41.4 & $2 \cdot 2$ & $40 \cdot 3$ & 4.2 \\
\hline CD8 (\%) & $7 \cdot 0$ & 1.7 & $6 \cdot 3$ & $1 \cdot 0$ & $7 \cdot 7$ & $2 \cdot 5$ \\
\hline CD4:CD8 & $6 \cdot 1$ & $1 \cdot 3$ & $6 \cdot 6$ & 0.9 & $5 \cdot 5$ & $2 \cdot 4$ \\
\hline \multicolumn{7}{|l|}{ Spleen } \\
\hline CD4 (\%) & $41 \cdot 1$ & 3.9 & 39.4 & 4.9 & $40 \cdot 7$ & 7.3 \\
\hline CD8 \% & $42 \cdot 8$ & 3.5 & $40 \cdot 1$ & 6.9 & 31.0 & $2 \cdot 8$ \\
\hline CD4:CD8 & 1.0 & 0.1 & $1 \cdot 1$ & 0.2 & $1.4^{*}$ & 0.1 \\
\hline
\end{tabular}

Mean value was significantly different from those for the other treatment groups: ${ }^{\star} P<0.05$

† For details of treatments and procedures, see pp. 484-485.

\section{Discussion}

The GALT is highly selective with regard to recognition of antigens. The microenvironment prevents an immune response to food antigens by actively suppressing the function of immunocompetent cells. Perturbation of the microenvironment, e.g. by infection or toxic insults, may result in an immune response to orally-applied antigens, which in turn might contribute to the development of food allergies or chronic inflammatory diseases of the gut. In this context, the role of plant lectins, natural constitutents of many cereals, legumes and vegetables, in the induction of a secondary immune response to an orally-applied antigen was examined.

The objective of the present study was to investigate whether non-nutritive constitutents in plant food, such as WGA, affect the response of the GALT towards dietary antigens. Using an in vivo animal model, the immunological potential of orally-applied WGA in the GALT was studied in immunized BN rats. OVA-specific antibodies (IgE and $\mathrm{IgG}$ ), proliferative responsiveness, IFN $\gamma$ secretion capacity and phenotypes of mesenteric lymphocytes as well as the release of RMCPII into serum as indicators of intestinal reactivity were quantified. In contrast to studies investigating the effect of high doses of xenobiotics, in the present study the administered dose of WGA was only ten times above the estimated intake of total dietary lectins consumed by subjects consuming vegetarian diets $(4.2 \mathrm{mg} /$ $\mathrm{kg}$ body weight; calculations based on data from Peumans \& van Damme, 1996). The results of the present study show that the allergic response (indicated as an increase in anti-OVA IgE) towards OVA was impaired by short-term treatment with WGA (27 $\mathrm{mg} / \mathrm{kg}$ body weight), whereas the production of RMCPII was elevated. These are the first results suggesting that relatively low doses of lectins such as WGA after oral exposure are able to impair the allergic response in immunized animals. Since other researchers have demonstrated that the effects of lectins on the gastrointestinal tract are fully or partially reversible (Bardocz et al. 1995), OVA was administered in the present study $1 \mathrm{~h}$ after the last WGA treatment. Pusztai et al. (1993) have shown that $2 \mathrm{~h}$ after the last feed intake over $60 \%$ of the WGA was still detectable in the small intestine, suggesting that at the time of the OVA administration the lectin was still present in the small intestine.

While the oral application of OVA to immunized control rats resulted in significantly increased anti-OVA IgE and IgG antibodies, WGA treatment inhibited such an increase, indicating that it may interfere with the regulation of $\operatorname{IgE}$ and IgG responses. The parenteral application of phytohaemagglutinin has also been shown to affect the $\operatorname{IgE}$ response towards OVA, depending on the timing of the phytohaemagglutinin injection (Astorquiza \& Sayago, 1984). In a further animal model, the oral application of the lectin jacalin from jackfruit (Artocarpus integrifolia) increased the IgE response towards OVA in a time- and dose-dependent way (Restum-Miguel \& Prouvost-Danon, 1985). Although all these studies suggest that lectins may function as modulators for the production of $\operatorname{IgE}$ antibodies, they reported exactly opposite effects to observations of the 
present study. Differences in the immunization protocols might be one reason for the contradictory results. In contrast to the present study, Restum-Miguel \& ProuvostDanon (1985) used mice instead of rats, which were at first sensitized orally with multiple doses of the lectin followed by subcutaneous immunization with OVA in combination with a synthetic adjuvant. It is currently not known whether modulation of antibody production is a general effect of lectins or whether only specific lectins exert such effects.

The intestinal mucosa of rats contains mast cells, which are a major source of serum allergic mediators such as histamine and RMCPII. This protease is released when mucosal mast cells degranulate, and it increases intestinal epithelial permeability without altering its structural integrity (Scudamore et al. 1995). As a consequence, antigen penetration of the intestinal epithelium could be enhanced. Evidence for activation of mucosal mast cells by WGA in the present study is suggested by the enhanced serum concentration of RMCPII observed in rats $4 \mathrm{~h}$ after the oral OVA challenge compared with the concentration in immunized control rats. Mediators such as histamine, which are secreted together with RMCPII by mucosal mast cells, may inhibit antibody production (OkitsuNegishi et al. 1988; de Pater-Huijsen et al. 1997). Since anti-OVA IgE production in immunized WGA-treated animals was not boosted by the oral OVA application, the enhanced release of mast cell mediators in these animals may have contributed to the lower serum anti-OVA IgE concentrations. At $5 \mathrm{~d}$ after the challenge, the serum RMCPII concentration returned to the baseline value, confirming that the effects of lectins are reversible (Bardocz et al. 1995). In contrast, a persisting elevated RMCPII serum concentration for at least $5 \mathrm{~d}$ after the oral challenge with $\mathrm{Hg}$ salts was seen in a similar model, although data for the immunized controls were comparable in both studies (Watzl et al. 1999a). Other researchers have also shown that WGA specifically activated peritoneal mast cells, indicated by an increased histamine secretion (Lansman \& Cochrane, 1980). Other lectins such as concanavalin A were not active. It has been speculated that mast cells are activated by the binding of the lectin to sugar residues on the $\operatorname{IgE}$ receptor, as well as by direct binding to $\operatorname{IgE}$ on mast cells (Ferreira et al. 1996). On stimulation by WGA, leucocytes from allergic patients showed a significant release of histamine, while leucocytes from IgE-deficient subjects did not respond (Shibasaki et al. 1992). This finding implies that binding of WGA to surface $\operatorname{IgE}$ is necessary for the histamine release, and that WGA does not directly interact with the leucocytes.

It has been shown in vitro that WGA dose-dependently induces IL-2 mRNA and IL-2 production of human lymphocytes (Reed et al. 1985; Kawakami et al. 1988). At the same time, WGA binds to the IL-2 receptor and decreases the number of high-affinity IL-2 receptors on Tcells, overall resulting in the inhibition of lymphocyte proliferation (Reed et al. 1985; Kawakami et al. 1988). On the basis of such a proposed mechanism and owing to the reversibility of the lectin effects (Bardocz et al. 1995), no adverse effects on lymphocyte proliferation were expected in the present study. At $5 \mathrm{~d}$ after the last WGA treatment, lymphocyte proliferation did not differ from that of immunized control animals, confirming the proposed mechanism.

Lectins, including WGA, trigger basophils to release IL4 and IL-13, both leading to elevated IgE synthesis (Haas et al. 1999). WGA in vitro induced IFN $\gamma$ production in murine mononuclear cells, suppressing IgE synthesis (Muraille et al. 1999). IFN $\gamma$ and IL-4 are regarded as critical for the regulation of IgE synthesis (Pene et al. 1988). This factor prompted us to determine the IFN $\gamma$ production of mesenteric $\mathrm{CD}^{+} \mathrm{T}$ lymphocytes. The results of the present study reveal that $5 \mathrm{~d}$ after the WGA application the capacity of mesenteric $\mathrm{T}$ lymphocytes to secrete IFNy was not impaired. At the time of the experiment, antibodies to measure IL-4 with ELISA were not commercially available.

The quantification of lymphocyte subpopulations from mesenteric lymph nodes and the spleen revealed that only phenotypes from splenic lymphocytes were changed after the WGA treatment. There were fewer $\mathrm{CD}^{+}$lymphocytes, resulting in significantly reduced CD4 : CD8 $(P<0 \cdot 05)$. WGA may affect differentiation into $\mathrm{CD}^{+}$lymphocytes or may enhance deletion of $\mathrm{CD}^{+}$lymphocytes. In contrast, using this model, it was shown that $\mathrm{Hg}$ treatment activated $\mathrm{CD} 4^{+}$lymphocytes in spleen and mesenteric lymph nodes (Watzl et al. 1999a). The present results further show that dietary WGA exposure induces systemic immune effects. Interestingly, no effects were observed in the primarily exposed T lymphocytes of the mesenteric lymph nodes $5 \mathrm{~d}$ after the last exposure. Any effect on this population was probably already reversed at this time point.

One major impact of WGA on the intestinal tissue is its permeability-enhancing effect. Several authors have demonstrated that WGA decreases or increases intestinal permeability as well as the trans-cellular permeability in confluent epithelial monolayers, depending on the molecular size of the permeability probes (Lorenzsonn \& Olsen, 1982; Sjölander et al. 1984, 1986). An in vitro model (Caco-2 cells) and a small-molecule permeability probe were used to investigate the effect of WGA in a dose range of up to $1 \mathrm{mg} / \mathrm{ml}$. Higher concentrations were shown to induce cytotoxicity in intestinal epithelial cells (Sjölander et al. 1984). None of the tested concentrations affected the permeability of the probe, indicating that pores within the cell membrane were not impaired by WGA. In contrast, with $\mathrm{HgCl}_{2}$ it was shown that the permeability for fluorescein was dose-dependently increased (Watzl et al. 1999a).

In conclusion, the overall data on the immunotoxic effects of WGA are currently rather contradictory. The majority of data have been generated in in vitro systems and data from animal studies often report contrasting results. This situation may be due to different immunization protocols as well as enteral $v$. parenteral application of lectins in these studies. The present data suggest that high dietary intakes of lectins such as WGA may interfere with the local allergic response towards oral antigens in the GALT. The mechanisms by which WGA suppresses IgE or $\operatorname{IgG}$ production and stimulates mast cell-mediator release are not well understood. In the context of food allergies, such an inhibitory effect of WGA on IgE production might be beneficial for individuals suffering from food allergies. 
Since the effects were seen only in the immunized rats, future studies should investigate the immunological effects of lectins in individuals with an allergic predisposition. In addition, more data should be available on the dietary exposure of individuals with a high intake of lectin-rich diets to evaluate more precisely their overall health effects.

\section{Acknowledgements}

This work was supported by a grant from the Landesregierung Baden-Württemberg, Germany (PUG P95003). The excellent technical assistance of M. Falk, M. Knoll, R. Lambertz and S. Filsinger is gratefully acknowledged.

\section{References}

Astorquiza MI \& Sayago S (1984) Modulation of IgE response by phytohemagglutinin. International Archives of Allergy and Applied Immunology 73, 367-369.

Bardocz S, Grant G, Ewen SWB, Duguid TJ, Brown DS, Englyst K \& Pusztai A (1995) Reversible effect of phytohaemagglutinin on the growth and metabolism of rat gastrointestinal tract. Gut 37, 353-360.

Brady PG, Vannier AM \& Banwell JG (1978) Identification of dietary lectin, wheat germ agglutinin, in human intestinal contents. Gastroenterology 75, 236-239.

Cordain L, Toohey L, Smith MJ \& Hickey MS (2000) Modulation of immune function by dietary lectins in rheumatoid arthritis. British Journal of Nutrition 83, 207-217.

de Pater-Huijsen FL, Pompen M, Jansen HM \& Out TA (1997) Products from mast cells influence $\mathrm{T}$ lymphocyte proliferation and cytokine production - relevant to allergic asthma? Immunology Letters 57, 47-51.

Ferreira RR, Cavada BS, Moreira RA, Olivieira JTA \& Gomes JC (1996) Charcteristics of the histamine release from hamster cheek pouch mast cells stimulated by lectins from Brazilian beans and concanavalin A. Inflammation Research 45, 442-447.

Freed DLJ (1999) Do dietary lectins cause disease? British Medical Journal 318, 1023-1024.

Haas H, Falcone FH, Schramm G, Haisch K, Gibbs BF, Klaucke J, Pöppelmann M, Becker WM, Gabius HJ \& Schlaak M (1999) Dietary lectins can induce in vitro release of IL-4 and IL-13 from human basophils. European Journal of Immunology 29, 918-927.

Huntley JF, Mackellar George A, Newlands FJ, Irvine J \& Miller HRP (1990) Mapping of the rat mast cell granule proteinases RMCPI and II by enzyme-linked immunosorbent assay and paired immunofluorescence. APMIS 98, 933-944.

Kawakami K, Yamamoto Y \& Onoue K (1988) Effect of wheat germ agglutinin on T lymphocyte activation. Microbiology and Immunology 32, 413-422.

Kilpatrick DC (1999) Immunological aspects of the potential role of dietary carbohydrates and lectins in human health. European Journal of Nutrition 38, 107-117.

Lansman JB \& Cochrane DE (1980) Wheat germ agglutinin stimulates exocytotic histamine secretion from rat mast cells in the absence of extracellular calcium. Biochemical Pharmacology 29, 455-458.

Lorenzsonn V \& Olsen WA (1982) In vivo responses of rat intestinal epithelium to intraluminal dietary lectins. Gastroenterology 82, 838-848.

Muraille E, Pajak B, Urbain J \& Leo O (1999) Carbohydratebearing cell surface receptors involved in innate immunity: Interleukin-12 induction by mitogenic and nonmitogenic lectins. Cellular Immunology 191, 1-9.
Nachbar MS \& Oppenheim JD (1980) Lectins in the United States diet: a survey of lectins in commonly consumed foods and a review of the literature. American Journal of Clinical Nutrition 33, 2338-2345.

Okitsu-Negishi S, Furusawa S, Yoshino K \& Abe T (1988) The suppressive effect of histamine on anti-DNP antibody production in mice. International Archives of Allergy and Applied Immunology 86, 391-399.

Ortega-Barria E, Ward HD, Keusch GT \& Pereira MEA (1994) Growth inhibition of the intestinal parasite Giardia lamblia by a dietary lectin is associated with arrest of the cell cycle. Journal of Clinical Investigation 94, 2283-2288.

Pene J, Rousset F, Chretien I, Bonnefoy JY, Spits H, Yokota T, Arai N, Arai K, Banchereau J \& de Vries JE (1988) IgE production by normal human lymphocytes is induced by interleukin-4 and suppressed by interferon $\gamma$ and $\alpha$ and prostaglandin E2. Proceedings of the National Academy of Sciences, USA 85, 6880-6884.

Peumans WJ \& van Damme EJM (1996) Prevalence, biological activity and genetic manipulation of lectins in food. Trends in Food Science and Technology 7, 132-138.

Pusztai A (1991) Plant Lectins. Cambridge: Cambridge University Press.

Pusztai A, Ewen SWB, Grant G, Brown DS, Stewart JC, Peumans WJ, van Damme EJM \& Bardocz S (1993) Antinutritive effects of wheat germ agglutinin and other $N$ acetylglucosamine-specific lectins. British Journal of Nutrition 70, 313-321.

Reed JC, Robb RJ, Greene WC \& Nowell PC (1985) Effect of wheat germ agglutinin on the interleukin pathway of human $\mathrm{T}$ lymphocyte activation. Journal of Immunology 134, 314-323.

Restum-Miguel N \& Prouvost-Danon A (1985) Effects of multiple oral dosing on $\operatorname{IgE}$ synthesis in mice: oral sensitization by albumin extracts from seeds of Jack fruit (Artocarpus integrifolia) containing lectins. Immunology 54, 497-504.

Scudamore CL, Thornton EM, McMillan L, Newlands GFJ \& Miller HRP (1995) Release of the mucosal mast cell granule chymase, rat mast cell protease-II, during anaphylaxis is associated with the rapid development of paracellular permeability to macromolecules in the jejunum. Journal of Experimental Medicine 182, 1871-1881.

Shaw AJ, Clothier RH \& Balls M (1990) Loss of trans-epithelial impermeability of a confluent monolayer of Madin-Darby canine kidney (MDCK) cells as a determinant of ocular irritancy potential. ATLA 18, 145-151.

Shibasaki M, Sumazaki R, Isoyama S \& Takita H (1992) Interaction of lectins with human IgE: IgE-binding property and histamine-releasing activity of twelve plant lectins. International Archives of Allergy and Immunology 98, 18-25.

Sjölander A, Magnusson KE \& Latkovic S (1984) The effect of concanavalin A and wheat germ agglutinin on the ultrastructure and permeability of rat intestine. International Archives of Allergy and Applied Immunology 75, 230-236.

Sjölander A, Magnusson KE \& Latkovic S (1986) Morphological changes of rat small intestine after short-time exposure to concanavalin A or wheat germ agglutinin. Cell Structure and Function 11, 285-293.

Tchernychev B \& Wilchek M (1996) Natural human antibodies to dietary lectins. FEBS Letters 397, 139-142.

Wang Q, Yu LG, Campbell BJ, Milton J \& Rhodes JM (1998) Identification of intact peanut lectin in peripheral venous blood. Lancet 352, 1831-1832.

Watzl B, Abrahamse SL, Treptow-van Lishaut S, Neudecker C, Hänsch GM, Rechkemmer G \& Pool-Zobel BL (1999a) Mercury enhances ovalbumin-induced antibody production and mucosal mast cell response. Food and Chemical Toxicology 37, 627-637. 
Watzl B, Neudecker C, Hänsch GM, Rechkemmer G \& PoolZobel BL (1999b) Short-term moderate aflatoxin $\mathrm{B}_{1}$ exposure has only minor effects on the gut-associated lymphoid tissue of Brown Norway rats. Toxicology 138, 93-102.
World Cancer Research Fund and American Institute for Cancer Research (1997) Food, Nutrition, and the Prevention of Cancer: a Global Perspective. 